\title{
Combined carbon and energy intensity benchmarks for sustainable retail stores
}

\author{
Ana Ferreira ${ }^{a,}{ }^{*}$, Manuel Duarte Pinheiro a, Jorge de Brito ${ }^{a}$, Ricardo Mateus ${ }^{b}$ \\ ${ }^{a}$ CERIS, Instituto Superior Técnico, Universidade de Lisboa, Av. Rovisco Pais, 1, 1049-001 Lisboa, Portugal \\ ${ }^{\mathrm{b}}$ CTAC, University of Minho, Department of Civil Engineering, Campus de Azurém, 4800-058 Guimarães, Portugal
}

\section{A R T I C L E I N F O}

\section{Article history:}

Received 2 May 2018

Received in revised form

27 September 2018

Accepted 5 October 2018

Available online 8 October 2018

\section{Keywords:}

Food and non-food retailers

Energy consumption

Energy-efficiency

Sustainability

Benchmarks

\begin{abstract}
A B S T R A C T
Retail stores are amongst the building typologies with the highest carbon (CI) and energy intensities (EI). However, previous studies have only explored the EI of food and non-food retailers. This study is the first of its kind to examine the link between $\mathrm{CI}$ and EI. Establishing the nature of this link will allow a deeper understanding of how to decarbonize the retail sector. Here, we hypothesised whether in retail low EI correlated with low $\mathrm{CI}$ and how corporate revenue affected these variables. "Best practice" and "conventional practice" benchmarks were then developed to assess retail buildings' sustainability. These represent missing and highly desirable tools in retail sustainable management.

Average EI and CI of food retailers were twice that of non-food retailers (EI-548 vs $238 \mathrm{kWh} / \mathrm{m}^{2} / \mathrm{y}$; $\mathrm{CI} 266$ vs $132 \mathrm{~kg} \mathrm{CO}{ }_{2} \mathrm{eq} / \mathrm{m}^{2} / \mathrm{y}$ ). The correlation found between $\mathrm{EI}$ and $\mathrm{CI}$ indicates that low energy consumption leads to low greenhouse gas (GHG) emissions. CI variability resulted mostly of energyefficiency strategies, of the energy production process and of GHG emissions from refrigeration systems. EI variability resulted mostly from store typology, volume and usage.

The proposed benchmarks help to set energy and carbon reference performance levels in retail buildings and to stimulate best sustainable practice amongst retailers.
\end{abstract}

() 2018 Elsevier Ltd. All rights reserved.

\section{Introduction}

Retail stores are amongst the building typologies with the highest carbon and energy intensity, placing this segment in the top 10 most carbon-intensive business sectors [1]. In addition, retail stores are responsible for $9 \%$ of the European building stock [2] with a standard energy intensity (EI) that ranges from 500 to $1000 \mathrm{kWh} /$ $\mathrm{m}^{2} / \mathrm{y}$, corresponding to three times that of conventional residential buildings and five times that of office buildings [3]. Furthermore, some of the retailers' activities like refrigeration are particularly carbon intensive in terms of direct emissions. Hydrofluorocarbon emissions from refrigeration systems and air conditioning can further increase the greenhouse effect because the global warming potential (GWP) of these gases is up to 11,700 times that of carbon dioxide [4]. Thus, retailers' overall carbon footprint is a high impact problem requiring a more sustainability-driven management

\footnotetext{
* Corresponding author.

E-mail addresses: anaferreiraleonardo@tecnico.ulisboa.pt (A. Ferreira), manuel pinheiro@tecnico.ulisboa.pt (M.D. Pinheiro), jb@civil.ist.utl.pt (J. de Brito) ricardomateus@civil.uminho.pt (R. Mateus).
}

solution.

Previous studies identified energy-efficiency strategies and best practices in food and non-food retail buildings [3,5-8]. Other studies have explored the link between energy consumption and carbon emissions from an energy efficiency perspective [9-13]. However, our current knowledge on retailers' carbon intensity $(\mathrm{CI})$ is extremely limited and the retail sector is missing $\mathrm{CI}$ benchmarks. This absence is partly due to the perceived difficulty in considering carbon emissions as a variable controllable by retailers. Nonetheless, the missing benchmarks are key to enable defining "best" and "conventional practice"; in turn important tools for sustainable management. Hence, both EI and CI need to be simultaneously addressed to effectively minimize climate change impacts related to the retail sector.

This study is unique in assessing a potential energy efficiency link between $\mathrm{CI}$ and EI. Two specific questions were tested within the retail sector using "EI", "Cl" and "revenue" as variables: a low EI profile corresponds to a low CI profile? and to what extent corporate revenue impacts these variables?. Additionally, benchmarks with "best practice" and "conventional practice" thresholds values were developed for both $\mathrm{CI}$ and EI, as (still missing) tools for more efficient energy management in the retail sector, providing knowledge 
regarding allowable limits for energy use. These benchmarks empower decision-makers to rank their stores according to what is known as the "what to" approach in decision theory [14], considering for the first time a linked action of EI and CI. They also support the design process of new or refurbished retail stores targeting efficient sustainability. Benchmarks are further expected to provide a framework for enhanced environmental performance, adding novel energy and carbon "best practice" reference levels for sustainability assessment tools.

\section{Materials and methods}

A qualitative comparison was made on the energy intensity (EI) and carbon intensity $(\mathrm{CI})$ patterns of retail stores. EI stands as the consumption of energy per unit of $\mathrm{m}^{2}$ of gross floor sales area per year (expressed in $\mathrm{kWh} / \mathrm{m}^{2} / \mathrm{y}$ ), whereas CI stands as the emission of Greenhouse Gas (GHG) per unit of $\mathrm{m}^{2}$ of gross floor sales area per year (expressed in $\mathrm{kg} \mathrm{CO} \mathrm{CO}_{2} \mathrm{eq} / \mathrm{m}^{2} / \mathrm{y}$ ). The initial sample comprised the 250 highest revenue retailers around the world, assessed according to publicly available data from the fiscal year 2016 [15]. However, inclusion and exclusion criteria were applied to the sample. Two inclusion criteria were defined: the companies had to be globally representative and have a mixed - food and non-food retail profile. Both non-food and food retailers had to be analysed because $\mathrm{EI}$ and $\mathrm{CI}$ vary considerably per typology of retail business [5]. Furthermore, retailers that operated online businesses were excluded, since no EI or CI analysis could be performed. The final sample was thus reduced to 242 retailers.

\subsection{Data selection procedure}

Five main data steps were considered for sample selection accordingly to public data (Fig. 1).

In step 1 (Desk research) and for each identified retailer, the following digital elements were searched: published sustainability/ corporate social responsibility (CSR) reports, annual reports, environmental policies and other energy or building data available online. A detailed content analysis of the information presented in retailers' sustainability/CSR reports was conducted, according to the variables "energy consumption" and "GHG emissions", adopting the methodology of Sullivan \& Gouldson [16]. Only the most recent (dating from 2016) and available sustainability/CSR retailers' reports were considered as to compare the most updated data. In step 2 (Retailer's categorization), retailers were divided into food or non-food groups according to the predominance of goods sold. The food typology included the categories of hypermarkets, superstores or supercentres, supermarkets, discount stores, convenience stores, neighbourhood market stores, grocery stores, liquor stores and cash $\&$ carry stores. The non-food typology included the categories of Do-It-Yourself (DIY) or home improvement stores, drug stores and pharmacies, department stores, shopping centres and neighbourhood malls, furniture decoration stores, household appliances and electronics stores, auto-shops, office supplies stores and other specialty stores. Even though some retailers had a mixed typology of store formats in their business portfolio, these were characterized as food or non-food retailers according to the predominant number of stores in each format. As a result, 120 of the studied retailers were classified as food retailers and 122 as non-food retailers (Fig. 2).

In step 3 (Sample screening), the sample was further screened to only include retailers which presented data on energy consumption and/or GHG emissions (39\% included considering the initial sample). All other retailers either did not have sustainability/CSR reports online (typically this information is disclosed within) or did not present such data in these reports. Further emails contacts requesting information were unfruitful. Most of the sampled retailers (90\%) had their data either certified by a third party or followed the standards of the Global Reporting Initiative. Additionally, the GHG emissions reported by retailers followed the GHG Protocol methodology for Scopes 1 and 2. The presented CIs are based on reported Scope 1 and Scope 2 emissions. Scope 1 covered all direct GHG emissions of a company including: i. stationary combustion for comfort heating or other industrial applications, ii. mobile combustion used in the operation of vehicles, and iii. fugitive emissions as an unintentional release of GHG from refrigerant systems and natural gas distribution [4]. Scope 2 covered all indirect GHG emissions from the consumption of purchased electricity, heat or steam [4].

There were important differences in the way retailers presented energy consumption and/or GHG emissions data and this influenced their consideration as a valid sample. On one hand, about 3\% of those retailers presented information about GHG emissions and/ or energy consumption but did not reveal the correspondent total sales floor area, so data normalization was not possible. Hence, these retailers were also excluded from the study. On another hand, $3 \%$ of retailers detailed the EI of each brand/typology of business operation and another $2 \%$ detailed EI and CI according to the country of operation. Hence, these retailers indicated more than

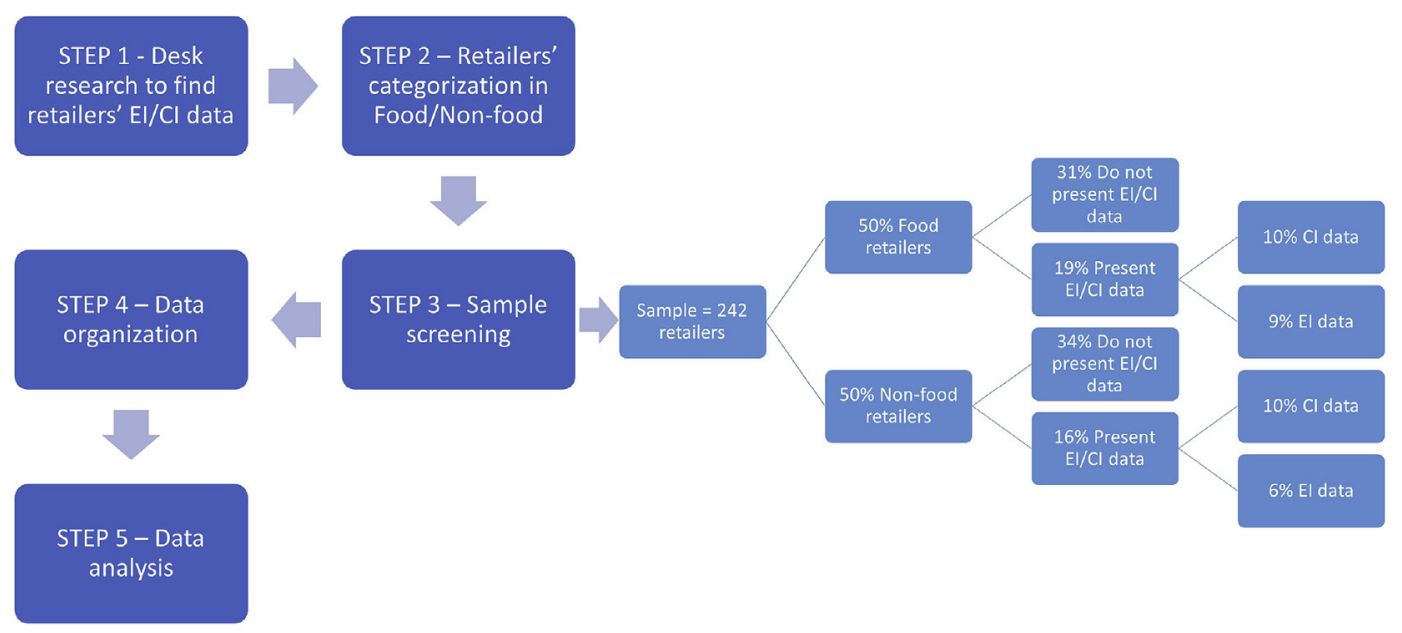

Fig. 1. Data selection procedure diagram. 


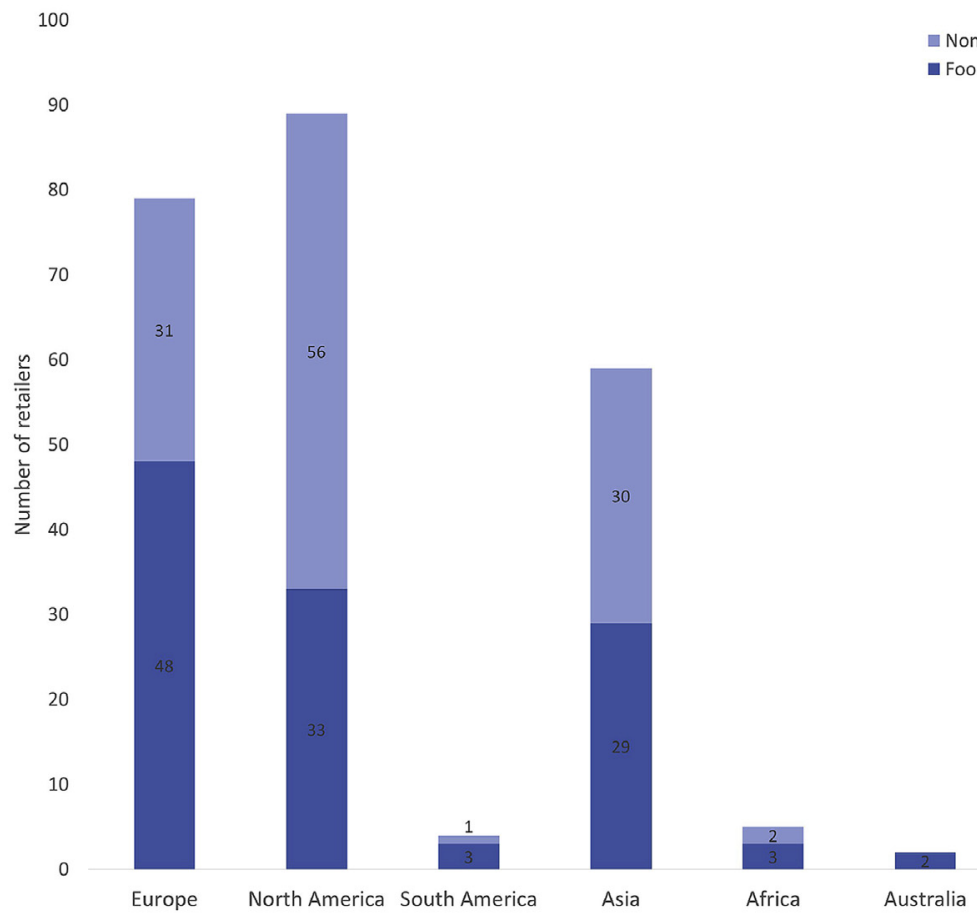

Non-food Retailers Food Retailers

Fig. 2. Distribution of food/non-food retailers per continent.

one $\mathrm{EI}$ or $\mathrm{CI}$. In terms of EI, data was collected from 34 food retailers (which provided 56 entries for EI) and from 25 non-food retailers (which provided 35 entries for $\mathrm{EI}$ ). In terms of $\mathrm{CI}$, data was collected from 37 food retailers (which provided 39 entries for $\mathrm{CI}$ ) and 35 non-food retailers (which provided 38 entries for $\mathrm{CI}$ ). As most retailers $(73 \%)$ reported energy consumption in the form of final energy, this was the unit chosen to calculate EI (one company used British thermal units (Btu) as a final energy unit, which was converted to $\mathrm{kWh}$ based on the Joule $(\mathrm{J})$ as a heat unit ( $1 \mathrm{kWh}=3.6 \mathrm{MJ}$ and $1 \mathrm{Btu}=1055 \mathrm{~J}$, therefore $1 \mathrm{kWh}=3412 \mathrm{Btu})$. The unit chosen to

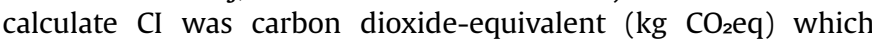
included direct and indirect GHG emissions (Scopes 1 and 2 of the GHG Protocol). Carbon dioxide-equivalent allows comparing GHG emissions through their global warming potential (GWP) in a set 100 -year time frame. Each retailer of the analysed sample had on average 3.120 stores and 5.5 million $\mathrm{m}^{2}$ of total selling space.

In step 4 (Data organization), the data was organized in a table that included the variables "revenue rank", "operational typology", "EI" and "CI" [dataset 1]. To ensure permanent access to the data that support the presented results, all internet references cited in our study were compiled in a data repository ([dataset 2]). In step 5 (Data analysis), the EI and CI of each retailer were analysed or calculated (normalizing total energy consumption/GHG emissions by total sales floor area per year), allowing to identify "best practice" and "conventional practice" benchmarks. The calculated EI and $\mathrm{CI}$ used time and floor area as normalized factors to match the metrics of retailers that presented $\mathrm{EI}$ and $\mathrm{CI}$ in such way. Furthermore, these were the only normalizing factors considered as the data did not support the analysis of additional ones (see additional information in $\S$ Section 4.5). The benchmarks were calculated applying the statistical operation median for "conventional practice" and first quartile (Q1) for "best practice". The "best practice" is the upper limit of the first quartile, corresponding to the boundary of the $25 \%$ lowest values. The "worst practice" is the lower limit of the third quartile $(\mathrm{Q} 3)$, corresponding to the boundary of the $75 \%$ highest values (Section 3.1) [dataset 1]. These benchmarks followed the methodology proposed by Castro et al. [17] for operating costs and resources consumption in healthcare buildings. In step 5 (Data analysis), a cluster analysis was also performed to identify possible segmentation patterns between the variables "EI", " $\mathrm{Cl}$ " and "retailer revenue". The cluster analysis was based in the Sum of the Squared Differences (SSE) between each observation and its group's mean (non-hierarchical or k-means cluster analysis). The number of segments was chosen when the SSE of all cases within the cluster dropped significantly, being closer to 0 than with any other segmentation arrangement. Additionally, and to corroborate results, the excel correlation function was performed on the same variables (Section 3.2) [dataset 1].

\section{Results}

\subsection{Retailer's EI and CI}

The EI and CI of food and non-food retailers were analysed, resulting in "best practice" and "conventional practice" benchmarks for the two groups. Concerning EI, food retailers' "conventional practice" ranged from 346 to $700 \mathrm{kWh} / \mathrm{m}^{2} / \mathrm{y}$, with "best practice" located below a $346 \mathrm{kWh} / \mathrm{m}^{2} / \mathrm{y}$ threshold. Non-food retailers' "conventional practice" ranged from 146 to $293 \mathrm{kWh} / \mathrm{m}^{2} / \mathrm{y}$, with "best practice" located below a $146 \mathrm{kWh} / \mathrm{m}^{2} / \mathrm{y}$ threshold. Hence, the best "conventional practice" mark of the non-food retailers is approximately half that of the food retailers. There was important EI variability for food retailers, reflecting a factor of 11 to 1 (Fig. 3). For non-food retailers, variability was also important, reflecting a factor of 6 to 1 (Fig. 4).

Variability in food retailers was almost double that of non-food retailers (Fig. 5). This can be explained by refrigeration systems which in retail stores can account for up to $50 \%$ of energy consumption [5].

Concerning $\mathrm{CI}$, food retailers' "conventional practice" ranged from 115 to $420 \mathrm{~kg} \mathrm{CO} 2 \mathrm{eq} / \mathrm{m}^{2} / \mathrm{y}$, with "best practice" threshold found below $115 \mathrm{kWh} / \mathrm{m}^{2} / \mathrm{y}$. Non-food retailers' “conventional 


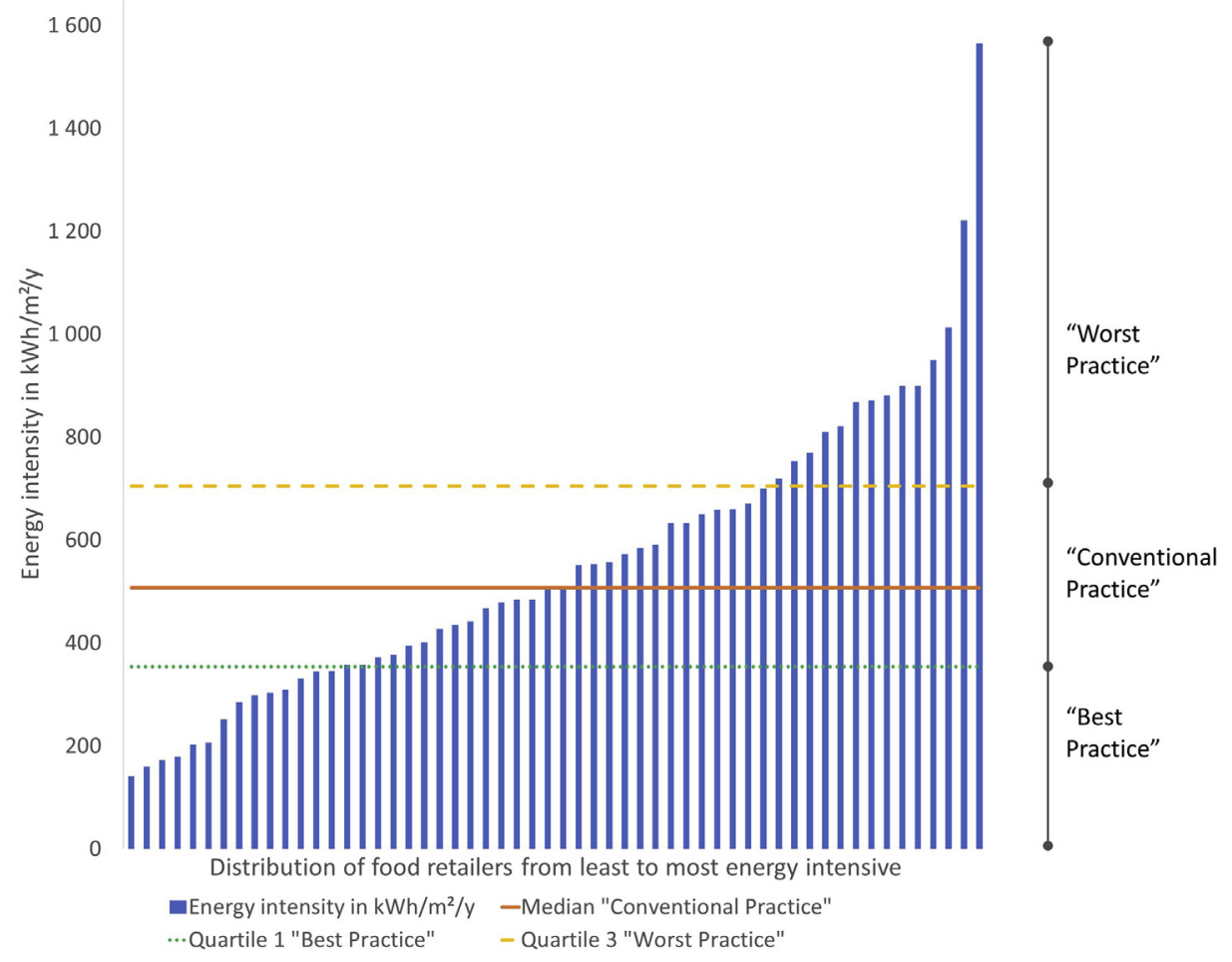

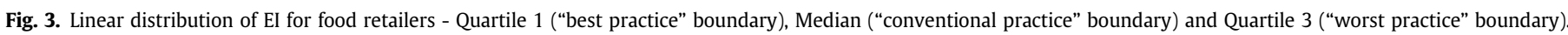

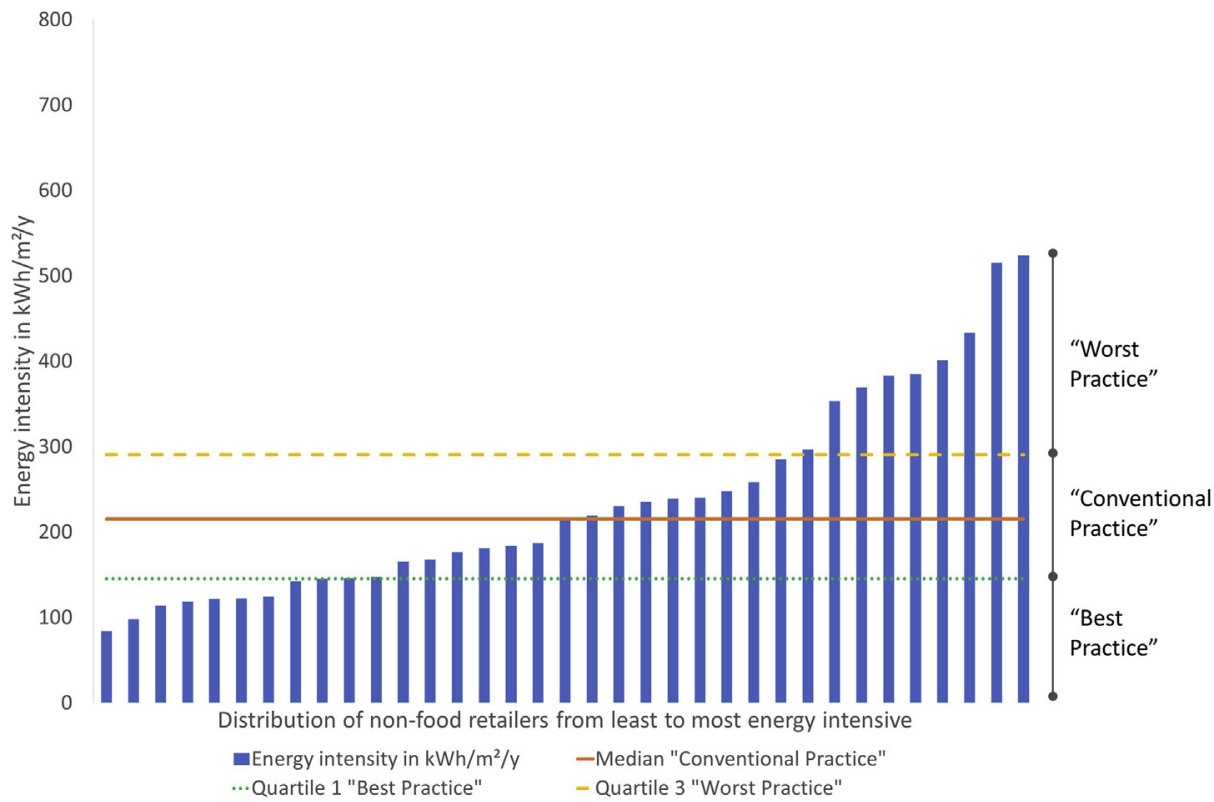

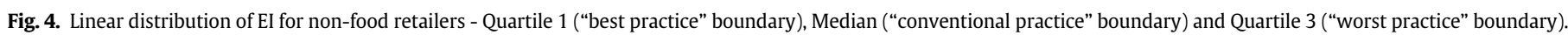

practice" ranged from 70 to $177 \mathrm{~kg} \mathrm{CO} 2 \mathrm{eq} / \mathrm{m}^{2} / \mathrm{y}$, with "best practice" threshold found below $70 \mathrm{kWh} / \mathrm{m}^{2} / \mathrm{y}$. For food retailers, variability was higher in CI than in EI, reflecting a factor of 18 to 1 (Fig. 6) and even higher for non-food retailers, reflecting a factor of 28 to 1 (Fig. 7).

Overall, there was a much greater range in food retailers' "conventional practice" than in non-food retailers (Fig. 8).

Table 1 presents a summary of the benchmarks identified for EI and $\mathrm{CI}$ in terms of threshold values for "best", "conventional" and "worst practice". Variability of CI was consistently higher than that of EI, and specifically 1.6 times greater in food retailers and 4.6 times greater in non-food retailers.

\subsection{Cluster analysis and correlation between EI, CI and revenue}

A non-hierarchical cluster analysis was performed to identify correlations amongst the variables "EI", "Cl" and "revenue". Only retailers that presented both EI and CI (24 food retailers and 21 

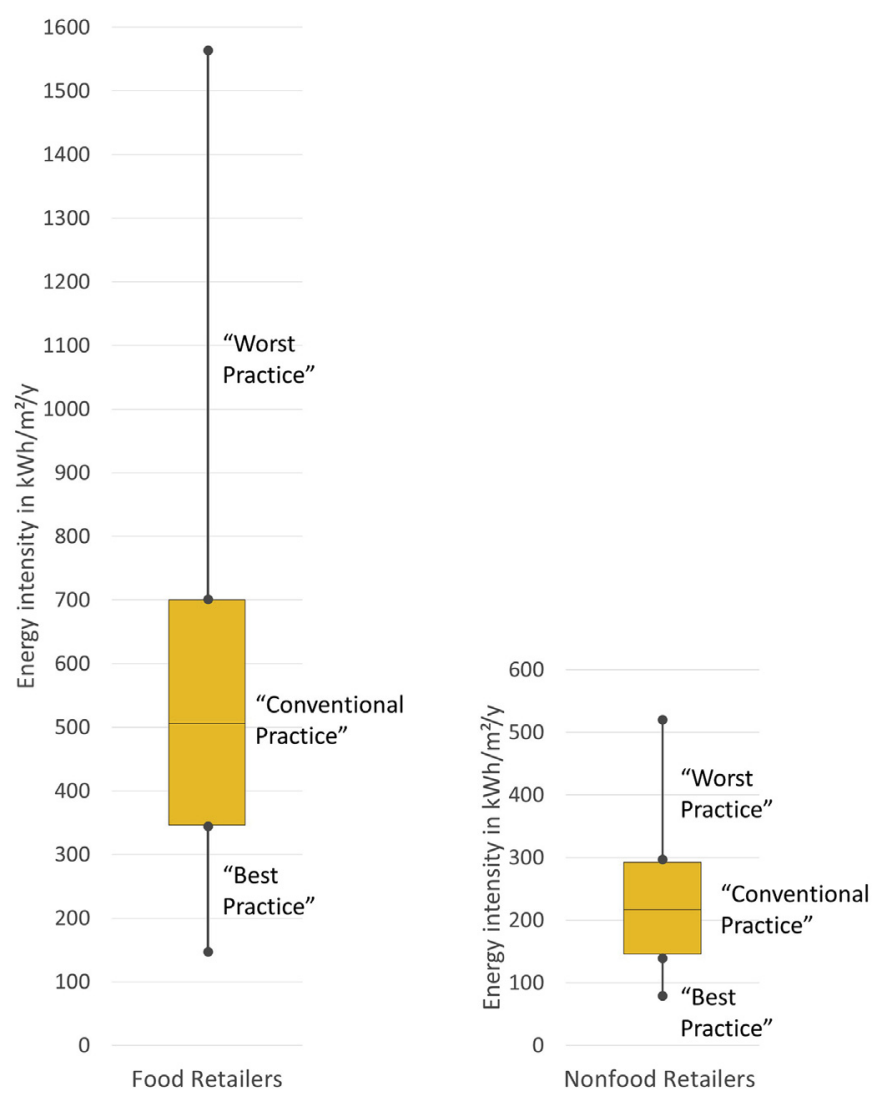

Fig. 5. Food and non-food retailers' EI benchmark.

non-food retailers) were included in the analysis.

In terms of $\mathrm{EI} v s \mathrm{CI}$, the cluster segmentation was evenly distributed between best and worst practice, both in food and in non-food retailers (Figs. 9 and 10). However, there were more retailers in clusters with EI and CI values below their group's average, which could be a positive sustainability tendency for the sector. There was a positive correlation between the variables EI and CI
( $\rho=0.58$ for food retailers and $\rho=0.53$ for non-food retailers).

In terms of EI vs revenue, the cluster segmentation was dispersed for food retailers and evenly distributed for non-food retailers between best and worst practice (Figs. 11 and 12), with a tendency for low EI to be associated with low revenue. There was a positive correlation between the variables EI and revenue for nonfood retailers $(\rho=0.61)$.

In terms of $\mathrm{CI} v s$ revenue, the cluster segmentation was dispersed for food retailers and evenly distributed for non-food retailers between best and worst practice (Figs. 13 and 14), with a tendency for low $\mathrm{CI}$ to be associated to low revenue. There was a positive correlation between the variables $\mathrm{CI}$ and revenue for nonfood retailers $(\rho=0.55)$.

\section{Discussion}

\subsection{Carbon (CI) and energy (EI) intensities linkage}

We explored the link between $\mathrm{CI}$ and EI to establish benchmarks for "best practice" and "conventional practice". Indeed, there was a positive correlation between EI and CI for both food retailers and non-food retailers. Additionally, and for non-food retailers, there was a positive correlation between revenue, EI and CI. In terms of EI, variability in food retailers was about twice that of non-food retailers. In opposition, variability of $\mathrm{CI}$ was higher in non-food retailers than in food retailers.

To the best of our knowledge, this is the first study to present $\mathrm{CI}$ benchmarks for retail stores, supporting the theory that to minimize retailers' carbon footprint, the first step required is to reduce energy consumption [5]. Combined CI and EI benchmarks placed best energy performance levels simultaneously under $346 \mathrm{kWh} /$ $\mathrm{m}^{2} / \mathrm{y}$ and $115 \mathrm{~kg} \mathrm{CO}$ eq $/ \mathrm{m}^{2} / \mathrm{y}$ for food retailers and under $146 \mathrm{kWh} /$ $\mathrm{m}^{2} /$ and $70 \mathrm{~kg} \mathrm{CO} \mathrm{eq}_{2} / \mathrm{m}^{2} / \mathrm{y}$ for non-food retailers. These findings are novel as other reference studies have focused exclusively on EI $[3,6,18]$.

We found overall lower "conventional practice" EI levels for food retailers than those proposed by Tassou et al. $\left(548 \mathrm{kWh} / \mathrm{m}^{2} / \mathrm{y} v s\right.$ $770 \mathrm{kWh} / \mathrm{m}^{2} / \mathrm{y}$ ) [6]. In terms of "best practice" EI levels, our results were also lower than those of Galvez-Martos et al. [3] ( $<346 \mathrm{kWh} /$ $\mathrm{m}^{2} / \mathrm{y} v s<500 \mathrm{kWh} / \mathrm{m}^{2} / \mathrm{y}$ ). The results for "conventional practice" EI

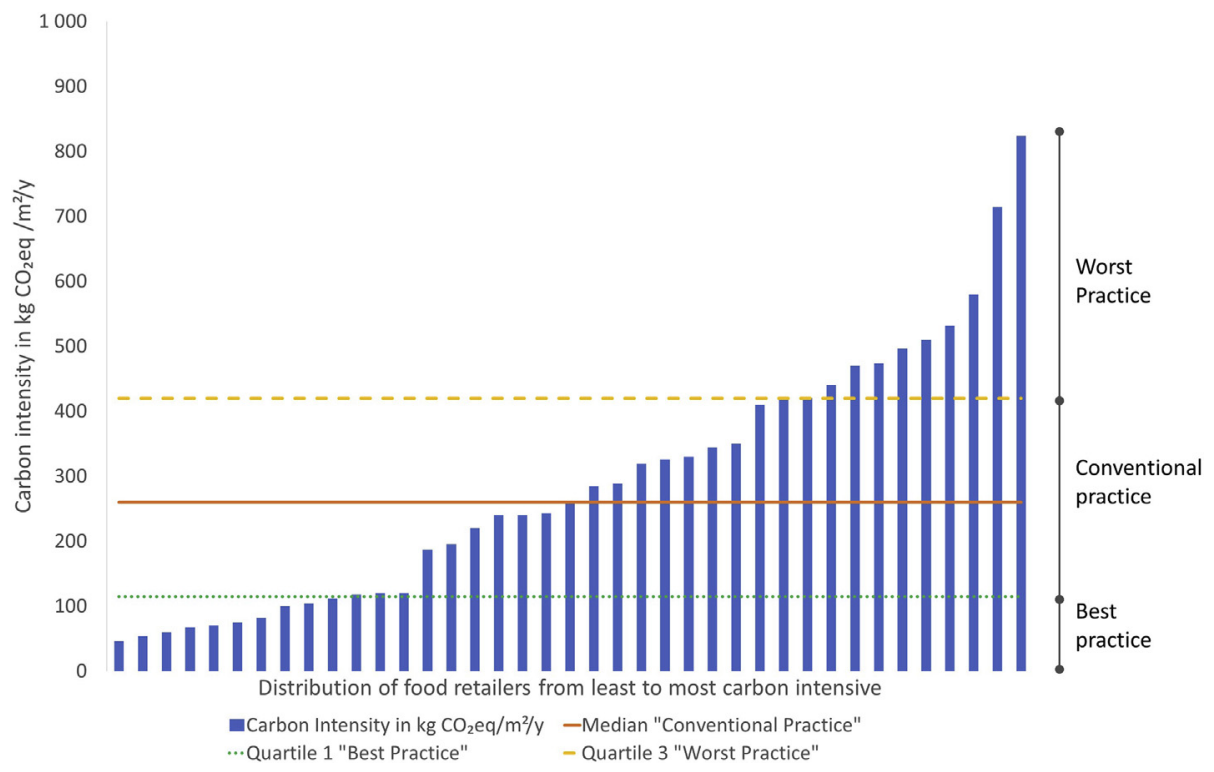

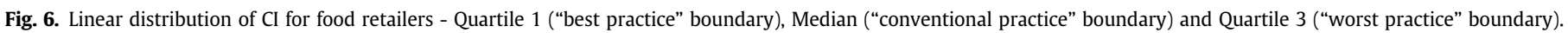




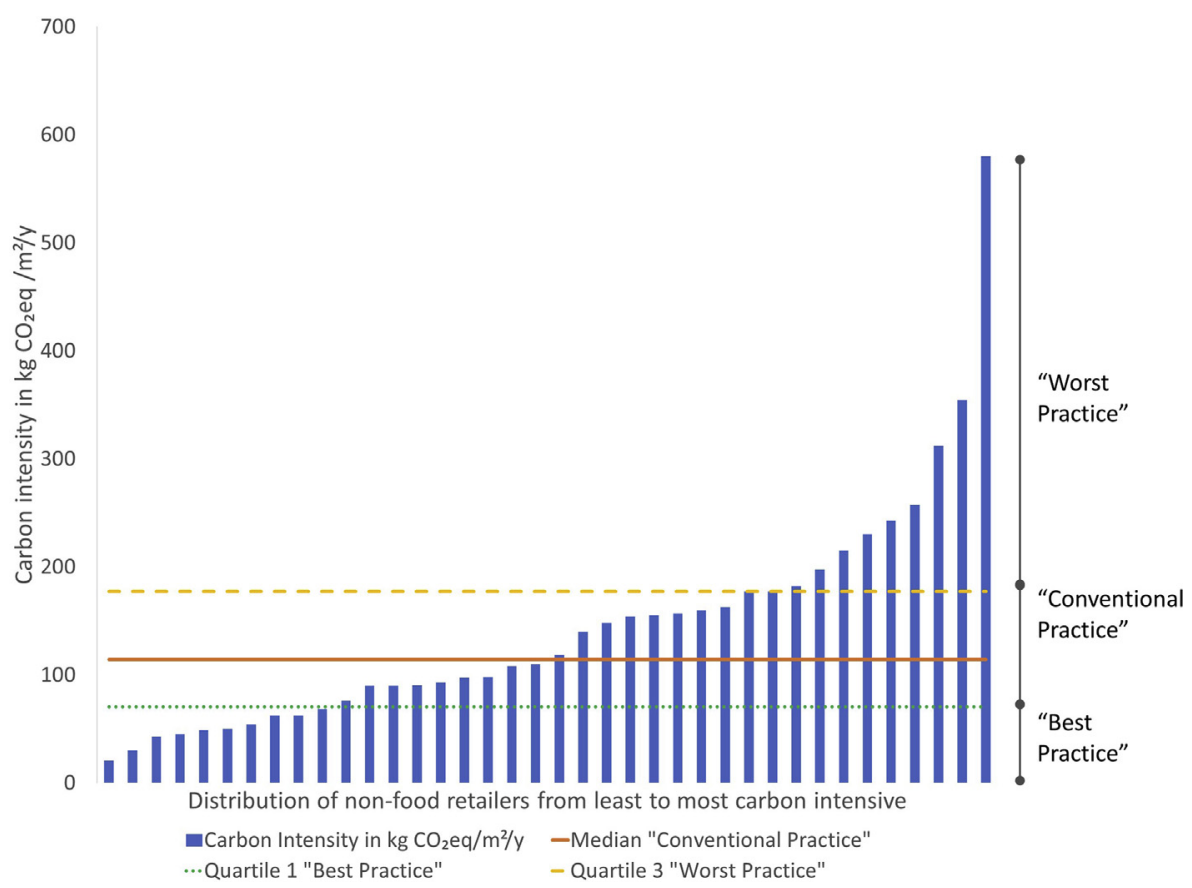

Fig. 7. Linear distribution of $\mathrm{Cl}$ for non-food retailers - Quartile 1 ("best practice" boundary), Median ("conventional practice" boundary) and Quartile 3 ("worst practice" boundary).

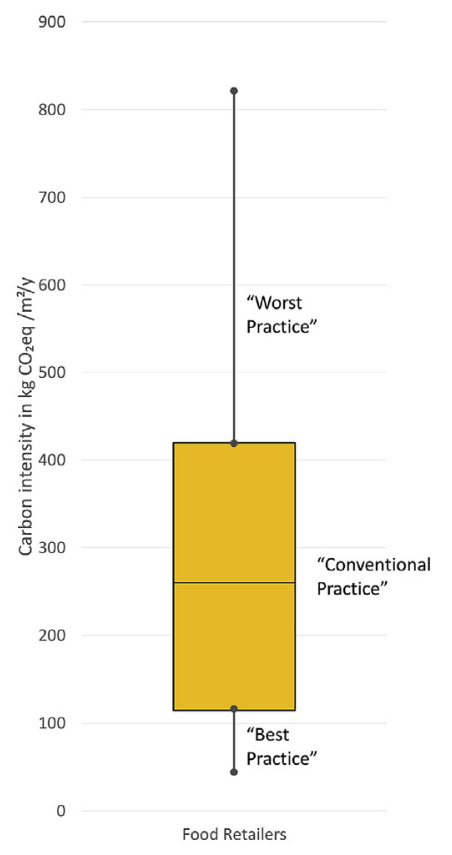

900

800

$$
700
$$

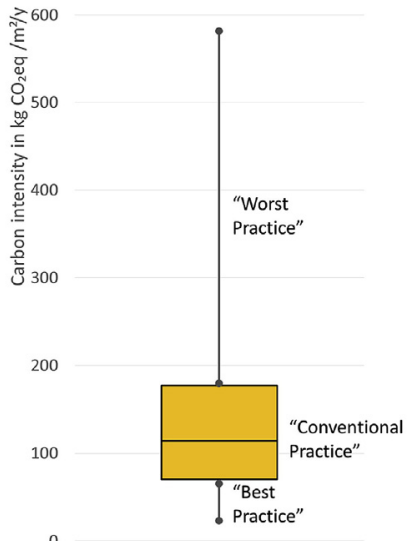

0

Nonfood Retailers
Fig. 8. Food and non-food retailers' CI benchmark.

levels of non-food retailers are comparable to those of GalvezMartos et al. [3], with an average EI about half that of food retailers $\left(238 \mathrm{kWh} / \mathrm{m}^{2} / \mathrm{y}\right.$ for non-food retailers vs $548 \mathrm{kWh} / \mathrm{m}^{2} / \mathrm{y}$ for food retailers in our study). The overall EI range presented here across all retail stores is about half of that proposed by Energy Star [18] (84-1.565 $\mathrm{kWh} / \mathrm{m}^{2} / \mathrm{y}$ vs 315-2.517 $\left.\mathrm{kWh} / \mathrm{m}^{2} / \mathrm{y}\right)$. However, the variability was comparable to that of Energy Star [18], with "best practice" retailers using at least six times less the energy of "worst practice" retailers.

The positive correlation between the variables $\mathrm{EI}$ and $\mathrm{CI}$ is consistent with the findings of Schönberger, Martos and Styles [5], who indicated the carbon footprint of retail companies to be highly dependent on electricity use. CI variability was greater than that of EI, particularly for non-food retailers. Refrigerants can be responsible for up to $40 \%$ of the carbon emissions in food retailers, with electricity being responsible for up to 60\% [5]. For non-food retailers and because of the absence refrigeration systems, the ratio of GHG emissions from electricity is higher, which aggravates CI variability. In general terms, variability in $\mathrm{CI}$ is a result of energyefficiency strategies to decrease energy consumption, and of the production sources of the consumed energy (fossil vs. renewable energy). For food retailers, it is also a result of fugitive emissions from refrigeration systems [1]. Moreover, heating systems may also influence $\mathrm{CI}$, as well as the choice of refrigerant gas and refrigeration and HVAC systems' maintenance.

Results allow to conclude that store typology impacted EI, which is analogous to the findings of Tassou et al. [6] for food retailers. Indeed, hypermarkets consumed on average about the same energy than supermarkets $\left(591 \mathrm{kWh} / \mathrm{m}^{2} / \mathrm{y}\right.$ vs $\left.584 \mathrm{kWh} / \mathrm{m}^{2} / \mathrm{y}\right)$ and supermarkets consumed less energy than convenience stores ( $584 \mathrm{kWh} /$ $\mathrm{m}^{2} / \mathrm{y}$ vs $941 \mathrm{kWh} / \mathrm{m}^{2} / \mathrm{y}$ ), as evidenced by the retailers that specify EI

Table 1

EI and CI benchmark threshold values for "best", "conventional" and "worst practice”, for food and non-food retailers.

\begin{tabular}{|c|c|c|c|c|}
\hline & \multicolumn{2}{|c|}{ Energy Intensity $\left(\mathrm{kWh} / \mathrm{m}^{2} / \mathrm{y}\right)$} & \multicolumn{2}{|c|}{ Carbon Intensity $\left(\mathrm{kg} \mathrm{CO} 2 \mathrm{eq} / \mathrm{m}^{2} / \mathrm{y}\right)$} \\
\hline & Food retailer & Non-food retailer & Food retailer & Non-food retailer \\
\hline "Best practice" & $<346 \mathrm{kWh} / \mathrm{m}^{2} / \mathrm{y}$ & $<146 \mathrm{kWh} / \mathrm{m}^{2} / \mathrm{y}$ & $<115 \mathrm{~kg} \mathrm{CO}{ }_{2} \mathrm{eq} / \mathrm{m}^{2} / \mathrm{y}$ & $<70 \mathrm{~kg} \mathrm{CO} 2 \mathrm{eq} / \mathrm{m}^{2} / \mathrm{y}$ \\
\hline "Conventional practice" & $346-700 \mathrm{kWh} / \mathrm{m}^{2} / \mathrm{y}$ & $146-293 \mathrm{kWh} / \mathrm{m}^{2} / \mathrm{y}$ & $115-420 \mathrm{~kg} \mathrm{CO}{ }_{2} \mathrm{eq} / \mathrm{m}^{2} / \mathrm{y}$ & $70-177 \mathrm{~kg} \mathrm{CO}{ }_{2} \mathrm{eq} / \mathrm{m}^{2} / \mathrm{y}$ \\
\hline "Worst practice" & $>700 \mathrm{kWh} / \mathrm{m}^{2} / \mathrm{y}$ & $>293 \mathrm{kWh} / \mathrm{m}^{2} / \mathrm{y}$ & $>420 \mathrm{~kg} \mathrm{CO}{ }_{2} \mathrm{eq} / \mathrm{m}^{2} / \mathrm{y}$ & $>177 \mathrm{~kg} \mathrm{CO}{ }_{2} \mathrm{eq} / \mathrm{m}^{2} / \mathrm{y}$ \\
\hline
\end{tabular}




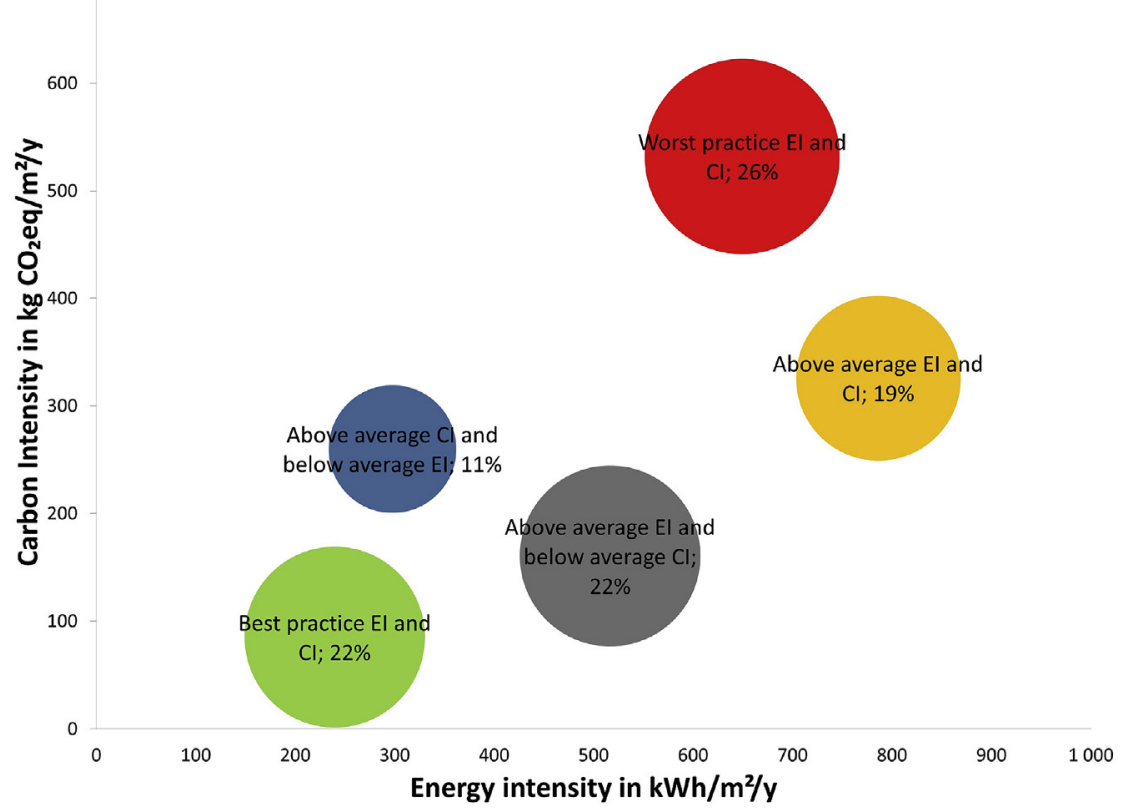

Fig. 9. Segmentation map of EI and CI for food retailers.

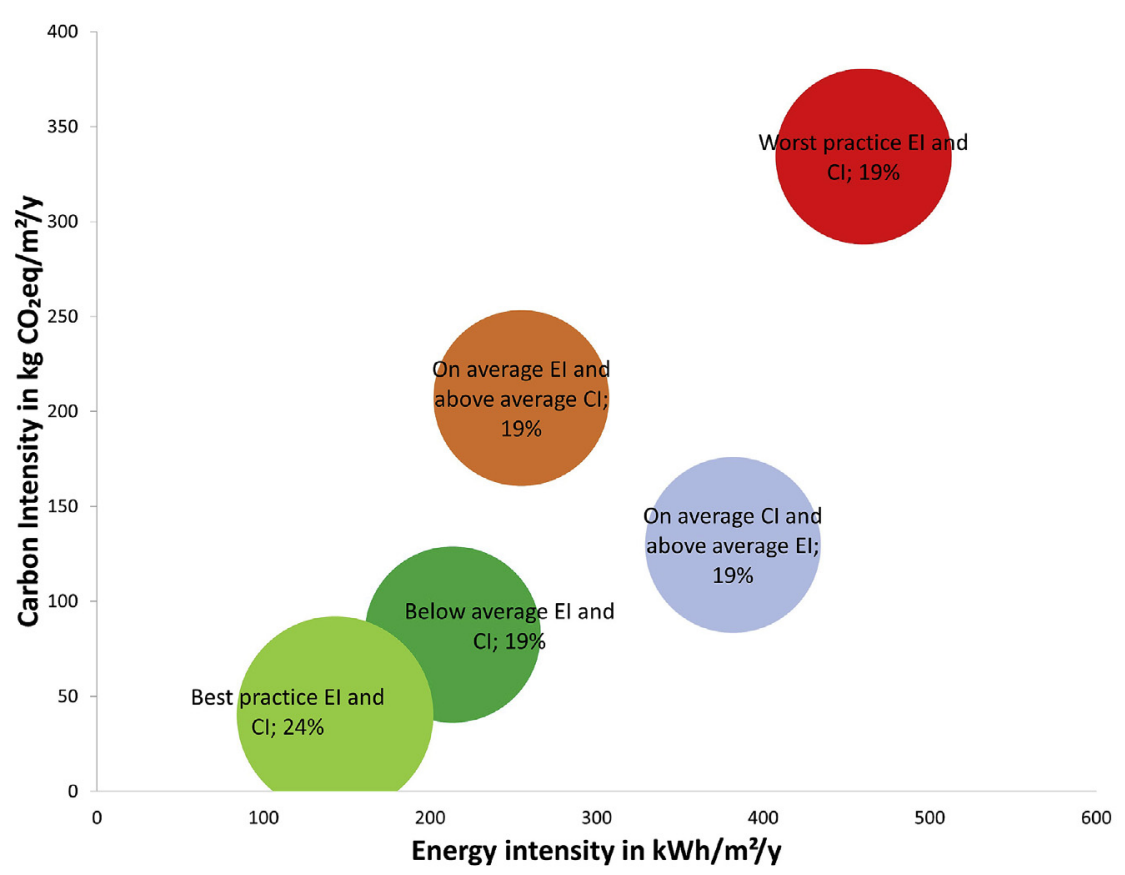

Fig. 10. Segmentation map of EI and CI for non-food retailers.

according to these store categories [19-21]. We found that store typology also impacted $\mathrm{CI}$, as the trend for most food retailers is for convenience stores to have on average higher $\mathrm{CI}\left(568 \mathrm{~kg} \mathrm{CO}{ }_{2} \mathrm{eq} / \mathrm{m}^{2} /\right.$ y) as they incorporate the most intense refrigeration-systems' typology per $\mathrm{ml}$ of aisle [6], followed by supermarkets $\left(273 \mathrm{~kg} \mathrm{CO}{ }_{2} \mathrm{eq} /\right.$ $\left.\mathrm{m}^{2} / \mathrm{y}\right)$, hypermarkets $\left(258 \mathrm{~kg} \mathrm{CO} \mathrm{CO}_{2} \mathrm{eq} / \mathrm{m}^{2} / \mathrm{y}\right)$ and discount stores $\left(226 \mathrm{~kg} \mathrm{CO} \mathrm{CO}_{2} \mathrm{eq} / \mathrm{m}^{2} / \mathrm{y}\right)$. The difference between average $\mathrm{EI} / \mathrm{CI}$ of supermarkets and hypermarkets is tenuous, as they tend to have similar display areas of refrigerated products, which is similar to the findings of Tassou et al. [6]. Supermarkets and discount stores had the highest EI variability per retail sub-type, reflecting a factor of 4 to 1 , followed by hypermarkets (a factor of 2 to 1 ) and convenience stores (a factor of 1.17 to 1 ). When analysing $\mathrm{CI}$ variability for food retailers, we found a similar breakdown per retail sub-type as that of EI, led by supermarkets (reflecting a factor of 15 to 1 ), followed by hypermarkets (a factor of 6 to 1 ), discount stores (a factor of 5 to 1 ) and convenience stores (a factor of 2 to 1 ). From these results, one may again infer a correlation between $\mathrm{EI}$ and $\mathrm{CI}$. EI/CI values for convenience stores are relatively stable as they are small in area and very energy and carbon intensive due to refrigeration systems. For other food retail sub-types, the higher variability (in particular that of $\mathrm{CI}$ ) shows that differences between the best and worst 


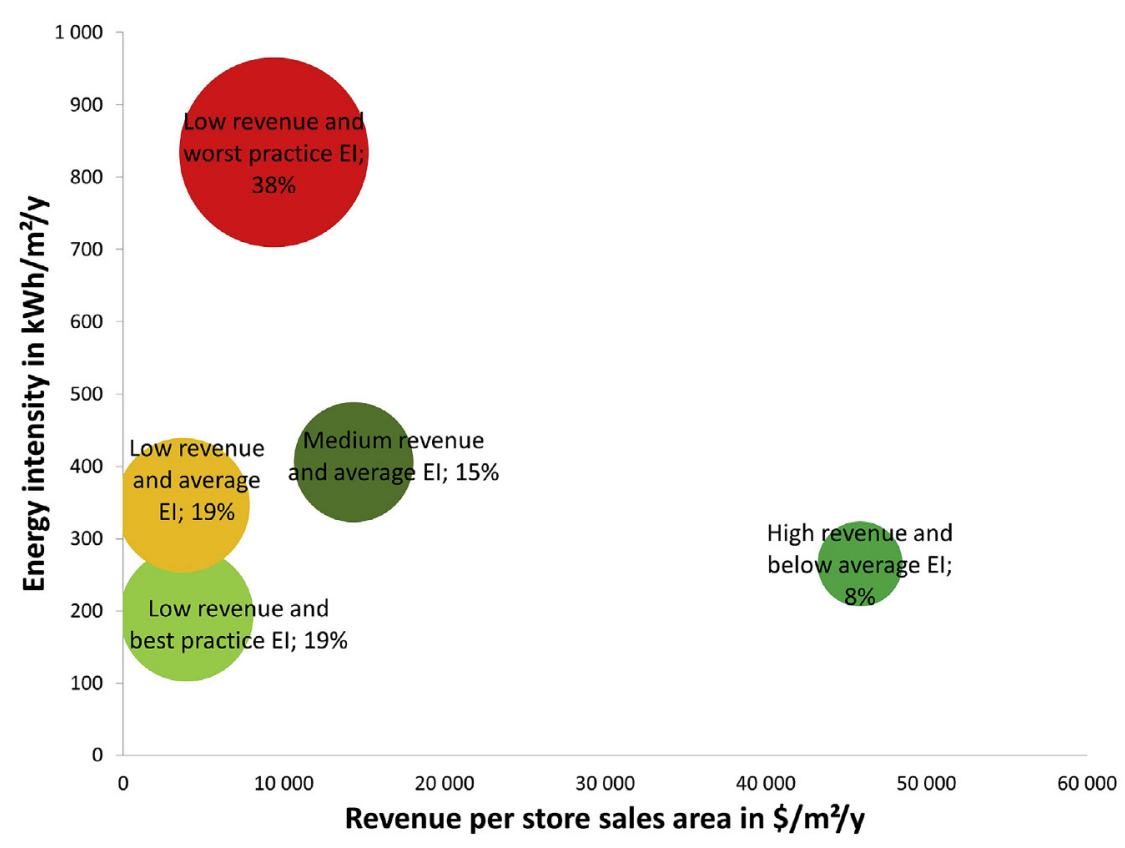

Fig. 11. Segmentation map of EI and retailer revenue (food retailers).

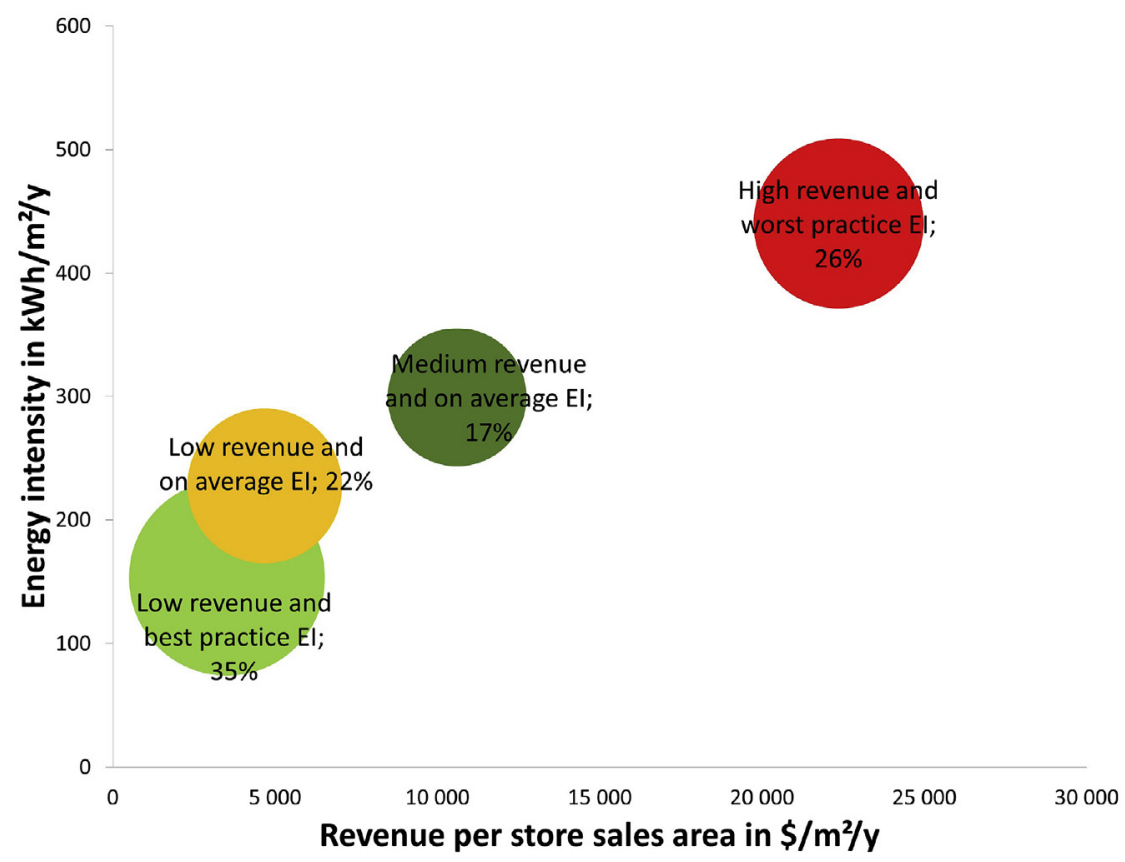

Fig. 12. Segmentation map of EI and retailer revenue (non-food retailers).

performing retailers are more extreme (namely in supermarket and discount stores) and likely related to other variables besides refrigeration systems, such as, merchandise display options, occupancy, location, equipment's efficiency, maintenance factors or the availability of cheap, locally produced electricity.

Store typology impacted the EI of non-food retailers as well, as the trend is for home improvement/DIY stores to have the lowest EI on average $\left(150 \mathrm{kWh} / \mathrm{m}^{2} / \mathrm{y}\right)$, followed by furniture decoration stores $\left(165 \mathrm{kWh} / \mathrm{m}^{2} / \mathrm{y}\right)$, auto-shops $\left(169 \mathrm{kWh} / \mathrm{m}^{2} / \mathrm{y}\right)$, electronics/ household appliances stores $\left(212 \mathrm{kWh} / \mathrm{m}^{2} / \mathrm{y}\right)$, drug stores/pharmacies $\left(220 \mathrm{kWh} / \mathrm{m}^{2} / \mathrm{y}\right)$, department stores $\left(283 \mathrm{kWh} / \mathrm{m}^{2} / \mathrm{y}\right)$ and apparel/footwear stores $\left(321 \mathrm{kWh} / \mathrm{m}^{2} / \mathrm{y}\right)$. This may be explained through marketing (and pricing) strategies: each store format has distinctive needs as how to effectively display merchandise and how to provide comfort and store ambiance for customers, which in turn will affect lighting, HVAC and equipment requirement. Likewise, store typology impacted $\mathrm{CI}$, with furniture decoration stores having the lowest $\mathrm{CI}$ on average $\left(60 \mathrm{~kg} \mathrm{CO} \mathrm{CO}_{2} / \mathrm{m}^{2} / \mathrm{y}\right)$, followed by auto shops $\left(82 \mathrm{~kg} \mathrm{CO} 2 \mathrm{eq} / \mathrm{m}^{2} / \mathrm{y}\right)$, electronics/household appliances stores ( $106 \mathrm{~kg} \mathrm{CO}{ }_{2} \mathrm{eq} / \mathrm{m}^{2} / \mathrm{y}$ ), home improvement/DIY stores ( $130 \mathrm{~kg}$ $\mathrm{CO}_{2} \mathrm{eq} / \mathrm{m}^{2} / \mathrm{y}$ ), drug stores/pharmacies ( $160 \mathrm{~kg} \mathrm{CO}{ }_{2} \mathrm{eq} / \mathrm{m}^{2} / \mathrm{y}$ ), apparel/ footwear stores $\left(161 \mathrm{~kg} \mathrm{CO}{ }_{2} \mathrm{eq} / \mathrm{m}^{2} / \mathrm{y}\right)$ and finally department stores 




Fig. 13. Segmentation map of $\mathrm{CI}$ and retailer revenue (food retailers).

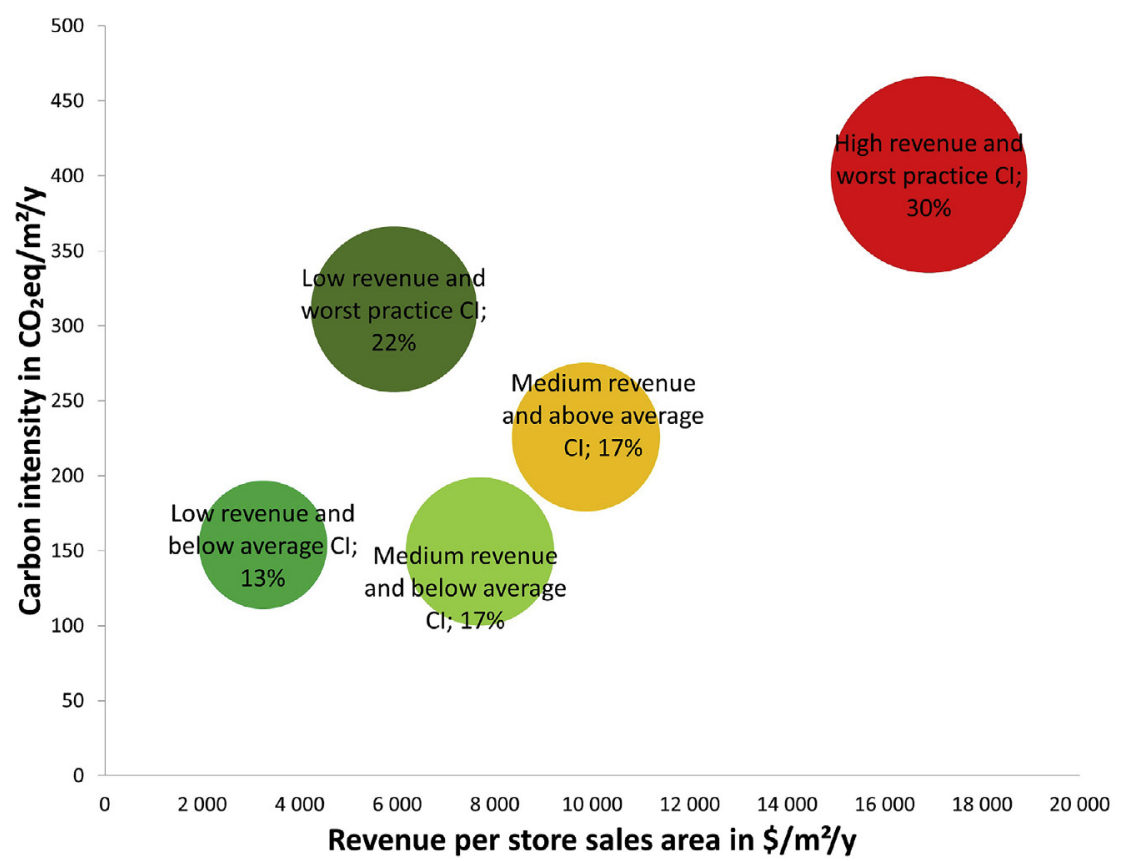

Fig. 14. Segmentation map of $\mathrm{CI}$ and retailer revenue (non-food retailers).

(175 kg CO$\left.{ }_{2} \mathrm{eq} / \mathrm{m}^{2} / \mathrm{y}\right)$. Drug stores/pharmacies, department stores and apparel/footwear stores stand as the most energy and carbon intensive retail sub-types, with the highest EI variability: a factor of 5 to 1 in electronics/household appliances stores and a factor of 3 to 1 in apparel/footwear and department stores. These are also the retail sub-types where luxury items retailers are found, with the highest EIs of their retail group. EI variability in home improvement/DIY stores was lower, reflecting a factor of 3 to 1 , as well as that of auto shops and drug stores/pharmacies, reflecting a factor of 2 to 1 . Furthermore, in terms of $\mathrm{CI}$, we found the greatest variability in electronics/household appliances stores and department stores (reflecting a factor of 12 to 1 ), followed by apparel/footwear stores (a factor of 8 to 1 ). CI variability in home improvement/DIY stores reflected a factor of 6 to 1 and all other retail sub-types reflected a factor of 3 to 1 (furniture decoration stores, auto shops and drug stores/pharmacies). Just as in food retailers, the similar breakdown of the most and least energy and carbon intensive non-food retailers attests to the correlation between $\mathrm{EI}$ and $\mathrm{CI}$, with $\mathrm{CI}$ variability also remaining higher than that of EI across all non-food retail sub-types. 
We found a tendency for store location to impact EI, as evidenced by the retailers that specified EI per retail sub-type and per country $[19,22,23]$; in a French retailer with hypermarket stores in France and in South America, EI variability reflected a factor of 1,8 to 1 (with a maximum value of $899 \mathrm{kWh} / \mathrm{m}^{2} / \mathrm{y}$ for Uruguayan stores and a minimum value of $484 \mathrm{kWh} / \mathrm{m}^{2} / \mathrm{y}$ for French stores); in a Spanish retailer with discount stores in Spain, Portugal, China and South America, EI variability reflected a factor of 3.07 to 1 (with a maximum value of $551 \mathrm{kWh} / \mathrm{m}^{2} / \mathrm{y}$ for Argentinian stores and a minimum value of $179 \mathrm{kWh} / \mathrm{m}^{2} / \mathrm{y}$ for Brazilian stores); in a French retailer with supermarket, auto shops and home improvement stores in France and in Portugal, EI variability reflected a factor of 1.05 to 1 for supermarkets, 1.19 to 1 for auto shops and 1.47 to 1 for home improvement stores. These results suggest that EI variability within in European countries is lower than that between Europe and other continents. Additionally, it shows that there are other more important factors affecting the EI than the climate conditions, since for instance, within Europe, stores located in countries with different climate conditions, have similar EI values.

Several factors may affect EI such as climate, opening hours, occupancy, behaviour and maintenance factors, building type, building age and equipment's efficiency [8]. Some companies have (on average) newer stores with newer equipment giving them an energy efficiency advantage. For instance, retailers that have applied green store concepts for their new buildings claim half [24] or a third [25] reductions of traditional EI energy consumption as a result of incorporating energy-efficient solutions. Ambient conditions may promote EI variability as warmer climates require more HVAC energy demand and can influence refrigeration systems' coefficient of performance (COP). Local electricity generation may also play a role as countries where energy is more expensive have additional drive to be more energy-efficient and to shift energy production to renewable sources. Culture and CSR policy/strategy should also impact EI (and CI) variability, as most of the retailers with the lowest EI/CI correspond to countries with advanced economies and sustainability ethic: Germany, Switzerland, Austria, Finland, Sweden or Norway. Nevertheless, Spyrou et al. [26] attest that system performance, weather conditions and building fabric were not as influential in the energy demand of large food retail buildings as usage, store size and volume [26]. This supports the point that the normalization of energy consumption per square meter per year and disregarding building volume, may influence variability due to the energy consumption of HVAC systems. From the data collection and analysis of this study, it is not possible to further determine the most relevant causal factors behind retailers $\mathrm{EI} / \mathrm{CI}$ variability. Further investigation is needed to identify the specific influence of overlooked variables on retail EI and CI, like location, retail sub-type, energy source, building size or building technologies.

The positive correlation found here between the variables revenue and $\mathrm{EI}$ and $\mathrm{CI}$ for non-food retailers indicates that companies with more revenue invest more in energy efficiency and in reducing their GHG emissions. Due to the absence of refrigeration systems, tackling EI and CI for non-food retailers may be more straightforward, mainly through energy-efficiency solutions and the use of renewable energy. In contrast, refrigeration systems may hinder the correlation between the variables revenue and EI and $\mathrm{CI}$ for food retailers, as these are respectively responsible for up to $50 \%$ and $40 \%$ of a store's EI and CI [5]. Nevertheless, the impact of energy savings alone in a company's profit, despite interesting ( $1 \%-5 \%$ of total operating costs), is still insufficient to make energy efficiency investments a top business priority [3]. In fact, a parsimonious approach seems transversal amidst retailers, as retailers tend to invest primordially in proved and tested solutions, with low payback periods that reap the maximum financial benefit [27].
Most of the retailers with the lowest $\mathrm{CI}$ are European and correspond to leading countries in sustainability ethic (Germany, Switzerland, Austria and Scandinavia). Simultaneously, many of the frontrunners are hard discount stores, which may be an indicator of low EI and CI related to optimal performance goals.

\subsection{Carbon and energy savings}

A combined approach of energy efficiency and low-carbon onsite or offsite electrical generation is suggested here as the most successful strategy to achieve large carbon savings. Other studies suggested similar strategies [12,28]. According to Jiang and Tovey [13], to achieve low carbon sustainability in large commercial buildings five aspects should be considered: awareness raising, energy management system, energy saving technologies, deployment of renewable energy and offsetting methods as a last resort. As no single parameter is responsible for low $\mathrm{EI}$ or $\mathrm{CI}$, an integrated design approach that considers climate, technology, occupant behaviour, and maintenance should be implemented to maximize energy efficiency and minimize GHG emissions.

Energy efficiency is the consensual priority amongst retailers when introducing sustainable high-performance solutions in their stores. This is largely because of the potential high cost savings and because energy efficiency contributes to the reduction of GHG emissions. Reducing energy demand ultimately means an increase in efficiency through a reduction in waste [29]. The most common energy efficiency solutions used by retailers are economically driven: photovoltaic energy produced on site, green energy offsetting, LED lighting and energy management are the most popular measures cited by retailers. In fact, building commissioning can account for $16 \%$ energy savings for existing buildings and $13 \%$ for new construction [30].

To decrease Scope 1 GHG direct emissions, namely stationary combustion for comfort heating, food retailers can recover waste heat from the refrigeration cycle, hence supressing the need for additional store heating [31-35]. To address fugitive emissions resulting from unintentional release of GHG from refrigerant systems, retailers can invest in gas leakage detection and improved maintenance in HVAC and refrigeration systems. The later can minimize food retailers' carbon footprint by up to $30 \%$ [3]. Gas transfer to $\mathrm{CO}_{2}$ in refrigeration systems also ranks high for European food retailers, because of its impact on the company's overall carbon footprint. In addition, to decrease Scope 2 GHG indirect emissions from the consumption of purchased electricity, retailers can invest in on-site production of renewable energy, in the purchase of green energy or in offsetting methods. Energy efficiency solutions minimising energy consumption are the first step to decrease emissions from the electrification process.

\subsection{Carbon and energy combined benchmarks}

Improved energy performance leads to lower costs, greater awareness of energy costs, better business performance and knowledge about energy management [3]. Simultaneously, the reduction of GHG emissions is associated with a concern for retailers' carbon footprint and with a desire to shift towards more eco-friendly energy sources. Indeed, carbon neutrality is an assumed goal for some companies [35-42], with retailers primarily targeting a reduction of their own emissions and then offsetting the remainder [1]. The combined carbon and energy benchmarks presented in this study enable retailers to understand up to what extent it is possible to increase their stores environmental performance, by comparing their $\mathrm{EI}$ and $\mathrm{CI}$ to that of best performing competitors. 


\subsection{Impacts}

Because so little aggregated data are analysed and published for the retail sector, the proposed benchmarks present "best practice" and "good practice" thresholds values that will be of use to both international or local retailers in terms of energy management, but also to architects and engineers when designing new or refurbished retail stores, providing key indicators (such as $\mathrm{EI}$ or $\mathrm{CI}$ ) to be used in the performance assessment of different design approaches. Indeed, thresholds values are useful for appropriate energy management, as they provide knowledge regarding allowable limits for the use of resources, thus contributing to sustainable decisionmaking. Given that each of the studied retailers operates hundreds of stores, the results show a key potential to boost EI and CI of retails stores, particularly when refurbishing or building new stores. By incorporating the "best practice" thresholds levels in green store concepts, retailers will certainly evolve towards maximum energy efficiency and carbon neutrality. Green building certification may also help in this matter, since it provides for an environmental-friendly construction and building operation framework, considering the commercial building's life cycle. In fact, this research may also be of interest for green building tools, as threshold values and performance targets, coupled with life cycle assessments, are also fundamental to perform a sustainability assessment. Albeit achieving a net zero energy building may still be too costly for most business owners, the variability of the data collected demonstrates an already available capacity to reduce energy demand by a factor of 3 and carbon footprint by a factor of 6 . As the retail sector converges on the need to decrease $\mathrm{EI}$ and $\mathrm{CI}$, the next step will certainly involve adapting current business practice towards complete carbon neutrality.

\subsection{Limitations}

Unavoidably, some of the information available online could be outdated as some retailers did not publish reports on a yearly basis. In addition, most of the analysed retailers that were excluded either did not publish sustainability or CSR reports or had such reports in a language other than English. Other retailers did not present their energy consumption nor their GHG emissions in a way that could be normalized into an intensity by year and square meter framework. The initial 250 retailers' sample was thus reduced to 84 retailers, potentially somewhat influencing the percentages and the correlations obtained. Nonetheless, the analysed retailers present aggregated data for 296.572 stores, which is an indicator of the representativeness of the sample. It is important to note that the available data only considered time and floor area as normalizing factors, so the proposed benchmarks were limited to the normalizing factors supported by the data. Retailers consider time and floor area as normalizing factors for EI and CI for its easy, though simplifying, interpretation. On the one hand, the benchmarked "best practice" threshold values expressed per $\mathrm{m}^{2}$ per year are used as business performance indicators that allow straightforward target-setting for strategic sustainable management. On the other hand, they may hide considerable levels of uncertainty that are difficult to quantify. Other authors reported similar difficulties $[14,16]$. In fact, to make comparisons of energy use or carbon emissions more accurate and robust, the analysis of other relevant normalizing factors, such as location, is necessary in future studies.

Third party verification of reports' data was not done for $14 \%$ of the total analysed retailers. Nonetheless, in order to preserve the maximum number of retailers in the sample, we assumed that their published sustainability or CSR reports was accurate. A critical analysis was performed to understand if data from these retailers could be biased. The results showed that retailers without third party verification were in line with their verified competitors, with the following differences in the coefficients of variation of the sample including all retailers $v s$ the sample excluding non-thirdparty-verified retailers): $50 \%$ vs $52 \%$ for the EI of food retailers, $49 \%$ vs $44 \%$ for the EI of non-food retailers, $66 \%$ vs $67 \%$ for the CI of food retailers, $72 \%$ vs $75 \%$ for the $\mathrm{CI}$ of non-food retailers.

Retailers with operational basis on a continent may have simultaneous activity in others. Nonetheless and for the geographic trend analysis, the company headquarters was defined as the most relevant location in terms of their sustainability strategy.

It is important to notice that identifying the most energetic effective retailers through $\mathrm{CI}$ or EI (particularly for food retailers) is not straightforward. This is mainly due to the considerable variation in the amount of refrigerated food that companies retailed as a proportion of their overall activity [1], with direct impact on their $\mathrm{EI} / \mathrm{Cl}$.

A growing number of retail companies target reducing $\mathrm{EI}$ and $\mathrm{CI}$ in their sustainability/CSR reports and some provide yearly comparison data on these parameters. However, and for most retailers, energy efficiency goals and progress indicators are not disclosed and the information regarding the EI of stores lacks universal standards, namely in the energy metric elected. Some retailers presented data expressed in primary energy [34,36,43-45], which was converted to final energy data, without having in consideration the energy losses that may occur in the conversion or transformation process and that can account for up to 30\% of energy consumption.

Lastly, a part of the energy consumption data was collected from a secondary source: from a project report of a retailer [46] and from the U.S. Department of Energy - Better Buildings Initiative [47,48]. These data were only used to analyse four retailers and it is assumed that data were reported therein using the same method as the other background data used in this study. This could have influenced the results but to a very limited extent due to their very low representation in our total sample.

\section{Conclusion}

The primary goal of the proposed benchmarks was to set EI and CI reference performance levels enabling the management and design of more sustainable retail stores. Combined CI and EI best practice threshold values are found simultaneously under $346 \mathrm{kWh} / \mathrm{m}^{2} / \mathrm{y}$ and $115 \mathrm{~kg} \mathrm{CO} 2 \mathrm{eq} / \mathrm{m}^{2} / \mathrm{y}$ for food retailers and under $146 \mathrm{kWh} / \mathrm{m}^{2} /$ and $70 \mathrm{~kg} \mathrm{CO} \mathrm{CO}_{2} \mathrm{eq} / \mathrm{m}^{2} / \mathrm{y}$ for non-food retailers. The positive EI-CI correlation implies that low levels of energy consumption lead to low levels of GHG emissions. In turn, this confirms the importance of targeting energy efficiency by decreasing $\mathrm{CI}$, accompanied by replacement with renewable energy consumption. The variability found in this study shows that according to "best practice", it is feasible to reduce EI in retail stores by a factor of 3 and $\mathrm{CI}$ by a factor of 6 , which would impact decisively and positively the environmental performance of the retail sector.

We promoted here energy and carbon efficiency in retail buildings by introducing still missing benchmarks for "conventional" and "best practice" amongst retailers, as well as identifying key elements contributing to EI and CI decrease, such as energy efficiency solutions and the use of energy from renewable sources. These findings are of immediate interest and application to retailers, architects, engineers, and policy makers when considering the design and operation of retail stores. Our ongoing research aims to further assess the influence of isolated variables on retail EI and $\mathrm{CI}$, like climate conditions of the location, retail sub-type, energy source, building size or building technologies. 


\section{Funding}

This work was supported by FCT - Fundação para a Ciência e Tecnologia [grant number PD/BD/127852/2016] under the Doctoral Program EcoCoRe - Eco-Construction and Rehabilitation. Support from CERIS and Instituto Superior Técnico is also acknowledged.

\section{Declaration of interest}

None.

\section{Appendix A. Supplementary data}

Supplementary data to this article can be found online at https://doi.org/10.1016/j.energy.2018.10.020.

\section{References}

[1] ENDS Carbon - University of Edinburgh Business School. UK Supermarkets 2009 carbon benchmark report, Edinburgh. 2009.

[2] Building Performance Institute Europe. Europe's buildings under the microscope. 2011. https://bpie.eu/wp-content/uploads/2015/10/HR_EU_B_under_ microscope_study.pdf. [Accessed 14 December 2016].

[3] Galvez-Martos J-L, Styles D, Schoenberger H. Identified best environmental management practices to improve the energy performance of the retail trade sector in Europe. Energy Pol 2013;63:982-94. https://doi.org/10.1016/ j.enpol.2013.08.061.

[4] WRI WBCSD. Greenhouse gas Protocol. 2016. http://www.ghgprotocol.org/. [Accessed 8 November 2016].

[5] Schönberger H, Martos JLG, Styles D. Best environmental management practice in the retail trade sector learning from frontrunners. 2013. https://doi.org/ $10.2791 / 1775$

[6] Tassou SA, Ge Y, Hadawey A, Marriott D. Energy consumption and conservation in food retailing. Appl Therm Eng 2011;31:147-56. https://doi.org/ 10.1016/j.applthermaleng.2010.08.023.

[7] Chou D, Chang C-S, Hsu Y-Z. Investigation and analysis of power consumption in convenience stores in Taiwan. Energy Build 2016;133:670-87. https:// doi.org/10.1016/J.ENBUILD.2016.10.010.

[8] Chung W, Hui YV, Lam YM. Benchmarking the energy efficiency of commercial buildings. Appl Energy 2006;83:1-14. https://doi.org/10.1016/ J.APENERGY.2004.11.003.

[9] Spyrou MS, Shanks K, Cook MJ, Pitcher J, Lee R. An empirical study of electricity and gas demand drivers in large food retail buildings of a national organisation. Energy Build 2014;68:172-82. https://doi.org/10.1016/ j.enbuild.2013.09.015.

[10] Li Y, Sha R. The evaluation of energy conservation development and sustainability of the retail industry in China. Energy Sources Part B Econ Plann Pol 2014;9:207-13. https://doi.org/10.1080/15567249.2011.567224.

[11] Evans B, Sidat S. The use of temporal factors for improved $\mathrm{CO} 2$ emissions accounting in buildings. Build Serv Eng Technol 2018;39:196-210. https:// doi.org/10.1177/0143624417753297.

[12] Jenkins DP. Using dynamic simulation to quantify the effect of carbon-saving measures for a UK supermarket. J. Build. Perform. Simul. 2008;1:275-88. https://doi.org/10.1080/19401490802566891.

[13] Jiang P, Keith Tovey N. Opportunities for low carbon sustainability in large commercial buildings in China. Energy Pol 2009;37:4949-58. https://doi.org/ 10.1016/J.ENPOL.2009.06.059.

[14] Sala S, Ciuffo B, Nijkamp P. A systemic framework for sustainability assessment. Ecol Econ 2015;119:314-25. https://doi.org/10.1016/ J.ECOLECON.2015.09.015.

[15] Deloitte, Global Powers of Retailing 2017. The art and science of customers. 2017. https://www2.deloitte.com/content/dam/Deloitte/global/Documents/ consumer-industrial-products/gx-cip-2017-global-powers-of-retailing.pdf. [Accessed 11 September 2018].

[16] Sullivan R, Gouldson A. Ten years of corporate action on climate change: what do we have to show for it? Energy Pol 2013;60:733-40. https://doi.org/ 10.1016/j.enpol.2013.05.025.

[17] Maria de Fátima Castro LB, Mateus Ricardo, Serôdio Francisco. Development of benchmarks for operating costs and resources consumption to be used in healthcare building sustainability assessment methods. Sustainability 2015;7: 13222-48. https://doi.org/10.3390/su71013222.

[18] Energy Star. DataTrends: energy use in retail stores. 2013. https://www energystar.gov/buildings/tools-and-resources/datatrends-energy-use-retailstores. [Accessed 14 December 2016].

[19] Guichard Perrachon Casino. Casino corporate social responsibility report. 2014. https:/www.groupe-casino.fr/en/wp-content/uploads/sites/2/2015/05/ Annual-Report-Groupe-Casino-2014_EN.pdf. [Accessed 21 October 2016].

[20] Carrefour. Carrefour sustainability report. 2015. http://www.carrefour.com/ sites/default/files/carrefour__2015_annual_activity_and_responsible commitment_report.pdf. [Accessed 2 November 2016].

[21] Auchan. CSR SECTION MANAGEMENT REPORT OF THE 2015, 2015, https:/ www.auchan-holding.com/uploads/files/modules/publications/1504255168 59a91cc02aa44.pdf. [Accessed 11 September 2018].

[22] Dia. Annual report. 2015. http://memoriaanual2015.diacorporate.com/? culture=en-GB. [Accessed 12 May 2017].

[23] Intermarché. Intermarché - Rapport développement durable. 2015. http:/ presse.mousquetaires.com/wp-content/uploads/2015/06/rapportrse_2015_ flipbook_complet.pdf. [Accessed 2 November 2016].

[24] EDEKA. Wie steigende Energiekosten den selbstständigen Lebensmitteleinzelhandel treffen. 2015. http://www.edeka-verbund.de/ Unternehmen/media/edeka_gruppe/gruppe/gruppenprofil/positionen/ energie/PP_Energie_Web_2.pdf. [Accessed 11 September 2018].

[25] Rewe. Rewe sustainability report. 2015. http://www.rewe-group.com/en/ nachhaltigkeit. [Accessed 21 November 2016].

[26] Spyrou MS, Shanks K, Cook MJ, Pitcher J, Lee R. An empirical study of electricity and gas demand drivers in large food retail buildings of a national organisation. Energy Build 2014;68:172-82. https://doi.org/10.1016/ J.ENBUILD.2013.09.015.

[27] Andrews CJ, Krogmann U. Explaining the adoption of energy-efficient technologies in U.S. commercial buildings. Energy Build 2009;41:287-94. https:// doi.org/10.1016/j.enbuild.2008.09.009.

[28] Thompson B. Green retail: retailer strategies for surviving the sustainability storm. J Retail Leisure Property 2007;6:281-6. https://doi.org/10.1057/ palgrave.rlp.5100079.

[29] Price S. The potential of renewable energy as a risk-mitigating factor. J Retail Leisure Property 2010;9:89-91. https://doi.org/10.1057/rlp.2010.4.

[30] Mills E. Building commissioning: a golden opportunity for reducing energy costs and greenhouse gas emissions in the United States. Energy Effic 2011;4 145-73. https://doi.org/10.1007/s12053-011-9116-8.

[31] Migros. Sustainability management. 2015. https://report.migros.ch/2015/en/ overview-of-migros/context-engagement/sustainability-management/. [Accessed 12 May 2017].

[32] Aldi, Aldi North Group. Sustainability report. 2015. http://www.aldi.pt/print/ responsabilidade/ALDI_North_Group_Sustainability_Report_2015_EN.pdf. [Accessed 11 November 2016].

[33] Metro. Metro group corporate responsibility report 2013/14. 2014. http:// reports.metrogroup.de/2013-2014/corporate-responsibility-report/. [Accessed 11 November 2016].

[34] Woolworths. 2015 INTEGRATED REPORT. 2015. https://www. woolworthsholdings.co.za/wp-content/uploads/2017/12/whl_2015 integrated_report.pdf. [Accessed 11 September 2018].

[35] Lidl. Rapports de durabilité. 2015. https://www.enrouteversdemain-lidl.be introduction/rapports-de-durabilite/? ga =2.152622129.923055288 1536665554-1973559847.1536665554. [Accessed 11 September 2018].

[36] IKEA. Sustainability report FY16. 2016. http://www.ikea.com/ms/en_US/img/ ad_content/IKEA_Group_Sustainability_Report_FY16.pdf. [Accessed 9 February 2017].

[37] Coop Group. Sustainability report. 2015. http://www.coop.ch/pb/site common/get/documents/coop_main/elements/ueber/geschaeftsbericht/ 2016/pdf/COOP_NHB 2015 e low.pdf. [Accessed 12 May 2017].

[38] ICA Gruppen. Annual report. 2015. http://www.icagruppen.se/en/ rapportportal/annual-report-2015/. [Accessed 12 May 2017].

[39] Norgesgruppen. Annual review. 2015. http://www.norgesgruppen.no/ globalassets/finansiell-informasjon/rapportering/ng_eng_summary_annual_ review_2015.pdf. [Accessed 12 May 2017]

[40] Kohl's_Corporation. Corporate social responsibility report. 2015. http://www kohlsgreen.com/media/pdfs/2015CSRReport-Kohls.pdf. [Accessed 23 February 2017]

[41] Kingfisher. Sustainability report. 2016. http://www.kingfisher.com/ sustainability/files/reports/cr_report_2016/2016_Sustainability_Report pdf\#ref sustainabilityreport. [Accessed 12 May 2017].

[42] Walmart Walmart. Global responsability report. 2015. https://cdn.corporate walmart.com/c0/24/2383f0674d27823dcf7083e6fbc6/2015-global-responsibility-report.pdf. [Accessed 21 October 2016].

[43] CVS Health. Corporate social responsibility report. CVS Health; 2015. https:// www.cvshealth.com/social-responsibility/corporate-social-responsibility/ annual-corporate-social-responsibility-reports. [Accessed 21 November 2016].

[44] Best Buy. Best buy corporate responsibility and sustainability. 2015. https:/ corporate.bestbuy.com/sustainability/. [Accessed 21 November 2016].

[45] Lowe's. Building momentum 2015 SOCIAL RESPONSIBILITY REPORT. 2015. https://1g0r7s45brd833po5f1d5yyb-wpengine.netdna-ssl.com/wp-content/ uploads/2016/04/lowes-2015-social-responsibility.pdf. [Accessed 11 September 2018].

[46] Lewis JS. LTD, sustainability and energy statement. 2016. http:/www.lidl-inwarlingham.co.uk/wp-content/uploads/2016/04/P234-R-001-Energy-andSustainability-Strategy-FINAL.pdf. [Accessed 30 January 2017].

[47] US Department of Energy. Walmart better buildings initiative. 2016. https:/ betterbuildingssolutioncenter.energy.gov/energy-data/Wal-Mart Stores, Inc. [Accessed 30 January 2017]

[48] US Department of Energy. Best buy better buildings initiative. 2016. https:// betterbuildingssolutioncenter.energy.gov/energy-data/Best Buy. [Accessed 30 January 2017]. 


\section{Further reading}

[1] Ferreira Santos, Sofia Ana. Combined carbon and energy intensity benchmarks for sustainable retail stores, vol. 1. Mendeley Data; 2018. https://doi.org/10. 17632/ww29xrsv56.1.

[2] Ferreira Santos, Sofia Ana. Combined carbon and energy intensity benchmarks for sustainable retail stores - CSR Reports, vol. 1. Mendeley Data; 2018. https:// doi.org/10.17632/gnygmhvv8d.1. 